\title{
Diabetic Hand Infections: Factors at Presentation Influencing Amputation and Number of Surgical Procedures
}

\author{
Sanjai Ramkumar ${ }^{1}$ Madhu Periasamy ${ }^{1}$ Praveen Bhardwaj ${ }^{1} \quad$ R Ravindra Bharathi $^{1} \quad$ Monusha Mohan ${ }^{1}$ \\ S Raja Sabapathy ${ }^{1}$ \\ ${ }^{1}$ Department of Plastic, Hand and Reconstructive Microsurgery, \\ Address for correspondence S. Raja Sabapathy, MS, MCh, DNB, \\ Ganga Hospital, Coimbatore, Tamil Nadu, India \begin{abstract}
FRCS (Edin), Hon. FRCS (Glasgow), Hon. FACS, Department of Plastic, Hand and Reconstructive Microsurgery, Ganga Hospital, 313, Mettupalayam Road, Coimbatore, Tamil Nadu, 641043, India
\end{abstract} \\ (e-mail: rajahand@gmail.com).
}

Indian J Plast Surg 2021;54:289-296.

\begin{abstract}
Background Diabetic hand infections are associated with significant morbidity and disability. Amputations cause permanent disability, and multiple surgical procedures lead to morbidity. Diabetic foot infections have been well-studied but literature on hand infections is limited. We undertook a retrospective study of patients with diabetic hand infections operated at our center to study the factors at presentation with significant association with amputation and number of surgical procedures.

Patients and Methods Demographic data of 51 patients was collected. The six parameters, namely, duration of diabetes, "onset of symptoms to presentation" interval, presence of comorbidities, HbA1c level, random blood sugar (RBS) levels at admission, and culture characteristics were selected for statistical analysis to find a relationship with the two outcome variables: number of procedures done and need for amputation.

Results On bivariate analysis, Gram-negative infection was found to have a significant relationship with the need for multiple of procedures $(p=0.014)$. The mean difference between the "onset of symptoms to presentation" interval between

Keywords

- diabetes

- hand infection

- amputation

- gram-negative infection

- wound infection the amputation/non-amputation groups (2.9 days, $p=0.04$ ) and the multiple procedures/non-multiple procedure groups (4.4 days, $p=0.02$ ) was found to be statistically significant. Presence of comorbidities, long duration of diabetes, $\mathrm{HbA} 1 \mathrm{c}$, and RBS levels at admission did not show any statistically significant association with the two outcome variables studied.

Conclusion In the present study, we found that infection with Gram-negative organisms is significantly related to the need for multiple surgical procedures. A delay in presentation can influence the risk of amputation as well as multiple procedures. Institution of early appropriate care is important to get a good outcome.

\section{Introduction}

Diabetic hand infections can result in significant morbidity and disability. Literature on diabetic hand infections is sparse

published online October 2, 2021

DOI https://doi.org/ $10.1055 / \mathrm{s}-0041-1735421$ ISSN 0970-0358

compared with diabetic foot infections. Mann and Peacock in 1977 stated that the importance of these infections is often referred to but seldom reported. ${ }^{1}$ Literature review done by them then showed only two recorded case reports.

(C) 2021. Association of Plastic Surgeons of India.

This is an open access article published by Thieme under the terms of the Creative Commons Attribution-NonDerivative-NonCommercial-License, permitting copying and reproduction so long as the original work is given appropriate credit. Contents may not be used for commercial purposes, or adapted, remixed, transformed or built upon. (https://creativecommons.org/licenses/by-nc-nd/4.0/). Thieme Medical and Scientific Publishers Pvt. Ltd. A-12, 2nd Floor, Sector 2, Noida-201301 UP, India
\end{abstract}


According to their study, $5 \%$ of all inpatients with hand infections are diabetics. ${ }^{1}$ Subsequent studies have quoted an incidence ranging from $0.7 \%$ to as high as $12 \% .^{2-4} \mathrm{~A}$ PubMed search for articles on diabetic hand infection from India provided three retrievable original articles; one each from the northern, eastern and southern parts of India. ${ }^{5-7}$ One of the main concerns among patients with diabetic hand infections is the risk of amputation and multiple surgical procedures which, in turn, influence the length of inpatient stay and the cost of care, which are the second common concern of the patients. This study was intended to find out the factors present at the time of arrival, which have a significant relationship with the risk of amputation and multiple surgical procedures.

\section{Patients and Methods}

A retrospective study on 51 diabetic patients, who were operated for hand infections at our hospital from August 2015 to October 2019, was done. The basic demographic and

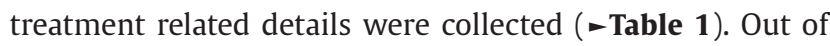
these variables, six parameters, namely, 1 ) duration of diabetes, 2) "onset of symptoms to presentation" interval, 3) presence of comorbidities, 4) HbA1c level, 5) random blood sugar (RBS) level at admission, and 6) culture characteristics were chosen for bivariate analysis to assess the relationship with the outcome variables, namely, the need for multiple procedures and amputation. We chose to study these six variables, since they have been the subject of examination in some earlier studies. ${ }^{8-11}$ Quantitative variables are summarized using mean and standard deviation (SD). Qualitative variables are summarized using frequency and proportion. Independent $t$-test and Mann-Whitney $\mathrm{U}$ test were used for comparison of selected quantitative variables. Mann-Whitney U test was used for analysis of non-parametric variables. Chi-square

Table 1 The list of variables studied

\begin{tabular}{|l|l|}
\hline Sl. no. & Variables studied \\
\hline 1 & Age \\
\hline 2 & Gender \\
\hline 3 & Duration of diabetes \\
\hline 4 & $\begin{array}{l}\text { Presence of comorbidities-hypertension, ischemic } \\
\text { heart disease, renal dysfunction, renal transplantation }\end{array}$ \\
\hline 5 & Previous amputation of limb/limb parts \\
\hline 6 & Diagnosis at presentation \\
\hline 7 & Onset-spontaneous/predisposing factors \\
\hline 8 & Primary treatment taken including home remedies \\
\hline 9 & Onset of symptoms to presentation interval \\
\hline 10 & Clinical and intraoperative findings \\
\hline 11 & $\begin{array}{l}\text { Laboratory parameters-RBS, fasting blood glucose, } \\
\text { glycosylated hemoglobin HbA1c, renal function test, } \\
\text { WBC count }\end{array}$ \\
\hline 12 & Culture and sensitivity of pus or tissue \\
\hline 13 & Type of surgery done \\
\hline 14 & Number of procedures done \\
\hline
\end{tabular}

Abbreviations: RBS, random blood glucose; WBC, white blood cell.

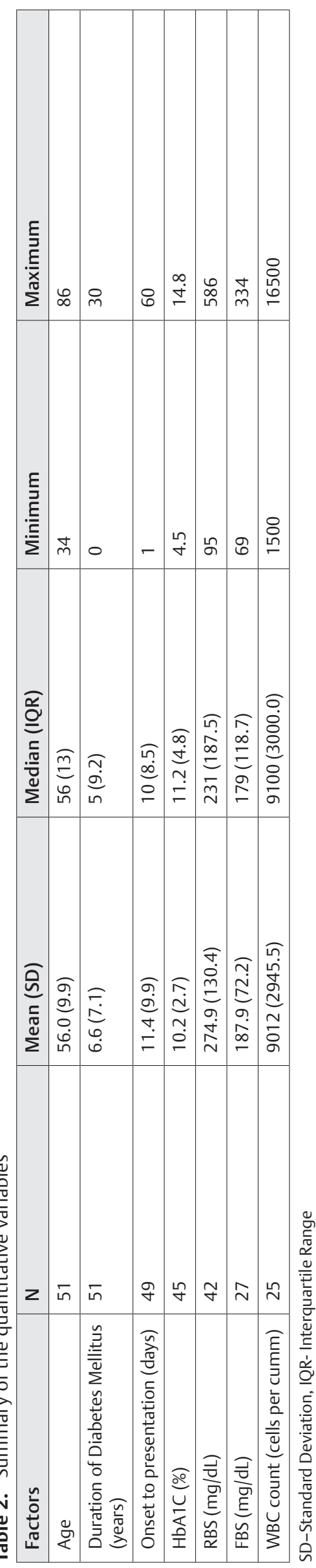


Table 3 Frequency of the variables studied

\begin{tabular}{|l|l|l|l|}
\hline Variables & Category & Frequency & Percent \\
\hline \multirow{2}{*}{ Gender $(n=51)$} & Male & 34 & 66.7 \\
\cline { 2 - 4 } & Female & 17 & 33.3 \\
\hline \multirow{2}{*}{ Presence of comorbidities $(n=51)$} & Present & 20 & 39.2 \\
\cline { 2 - 4 } & Absent & 31 & 60.8 \\
\hline \multirow{2}{*}{ HbA1C $(\%)(n=45)$} & $7 \%$ and above & 38 & 84.4 \\
\cline { 2 - 4 } & less than 7\% & 15.6 \\
\hline \multirow{2}{*}{ Culture characteristics $(n=23)$} & 200 and above & 7 & 66.7 \\
\cline { 2 - 4 } & Less than 200 & 33.3 \\
\hline \multirow{2}{*}{ Mode of injury $(n=51)$} & Gram-negative & 28 & 26.7 \\
\cline { 2 - 4 } & Gram-positive and others & 14 & 73.9 \\
\hline Amputation status $(n=51)$ & Spontaneous & 30 & 58.8 \\
\cline { 2 - 4 } & Injury & 21 & 41.2 \\
\hline \multirow{2}{*}{ Multiple procedures $(n=49)$} & Yes & 16 & 31.4 \\
\cline { 2 - 4 } & No & 35 & 68.6 \\
\hline
\end{tabular}

Abbreviation: RBS, random blood sugar.

and Fischer tests were used for comparison of the selected categorical variables. We obtained the approval of the Institutional Review Board for conducting the study.

All the study patients were admitted for surgical management. White blood cell (WBC) count, renal function tests (RFT), estimation of C-reactive protein (CRP), HbA1c, and glucose levels were measured on admission. Debridement, incision and drainage and amputations were done as emergency procedures, as per need. Adequate debridement was made to achieve healthy wound margins. The tissue or pus was sent for microbiological culture and antibiotic sensitivity. All the patients received intravenous cefuroxime $1.5 \mathrm{~g}$ on admission, and antibiotics were changed later, as per the culture and sensitivity report. Wounds were dressed daily, and redebridement and further reconstructive procedures were done as per the condition of the wound. Physiotherapy was initiated within 48 to 72 hours of surgery.

\section{Results}

A total of 51 patients were included in the study, and the mean age at presentation was $56 \pm 9.9$ years (range: $34-86$ years). In total, 66 percent $(n=34)$ of the patients were males. Twenty seven percent $(n=14)$ of the patients were diagnosed to have diabetes only at admission. The results are summarized in -Tables 2 and 3 . Thirty nine percent $(n=20)$ of patients had associated comorbid illnesses other than diabetes: systemic hypertension $(n=14)$, renal transplantation $(n=2)$, ischemic heart disease $(n=8)$, and cerebrovascular accident $(n=1)$. Five patients had associated diabetic foot ulcer. At admission, eight patients had a history of amputation of either upper or lower extremity parts due to diabetes.
Only one patient presented to us within 48 hours of onset of symptoms; in this case, the presenting feature was a bleb. The mean of the time interval from onset of symptoms to presentation at our hospital was 11.4 days with an SD of 9.9 days. During this period, 10 patients resorted to self-treatment. Six patients did not take any treatment due to lack of concern and ignorance regarding the potential consequences. The rest of the patients sought appropriate medical help late, as they took initial treatment in the form of local application of ointments or antibiotics and underwent inadequate drainage or debridement. None of the patients who underwent surgical treatment within 7 days of onset of symptoms had to undergo amputation.

The laboratory results are given in - Table 2. The microbiological examination of the infected pus or tissue was sent in 23 patients. Eleven cultures showed no growth, six grew Staphylococcal species (four were coagulase-negative Staphylococci [CoNS] and two were Staphylococcus aureus species), four grew Klebsiella species, and two grew Escherichia coli. The antibiotic sensitivity reports and admission details revealed that the empirical cefuroxime was changed to the sensitive antibiotic in five patients; the organisms were sensitive to cephalexin, ofloxacin and linezolid.

The clinical features ranged from cellulitis to necrotizing fasciitis, as shown in - Figs. 1,2. The etiology when analyzed showed that it was spontaneous in 30 of these patients, and the next common causes were traumatic injuries and prick injuries.

The surgical procedures ranged from incision and drainage of the abscess, debridement of infected tissue to soft tissue cover. Sixteen patients had to undergo amputation, and one post renal transplant patient underwent multiple procedures for shortening and closure of the digit. Eighteen patients 

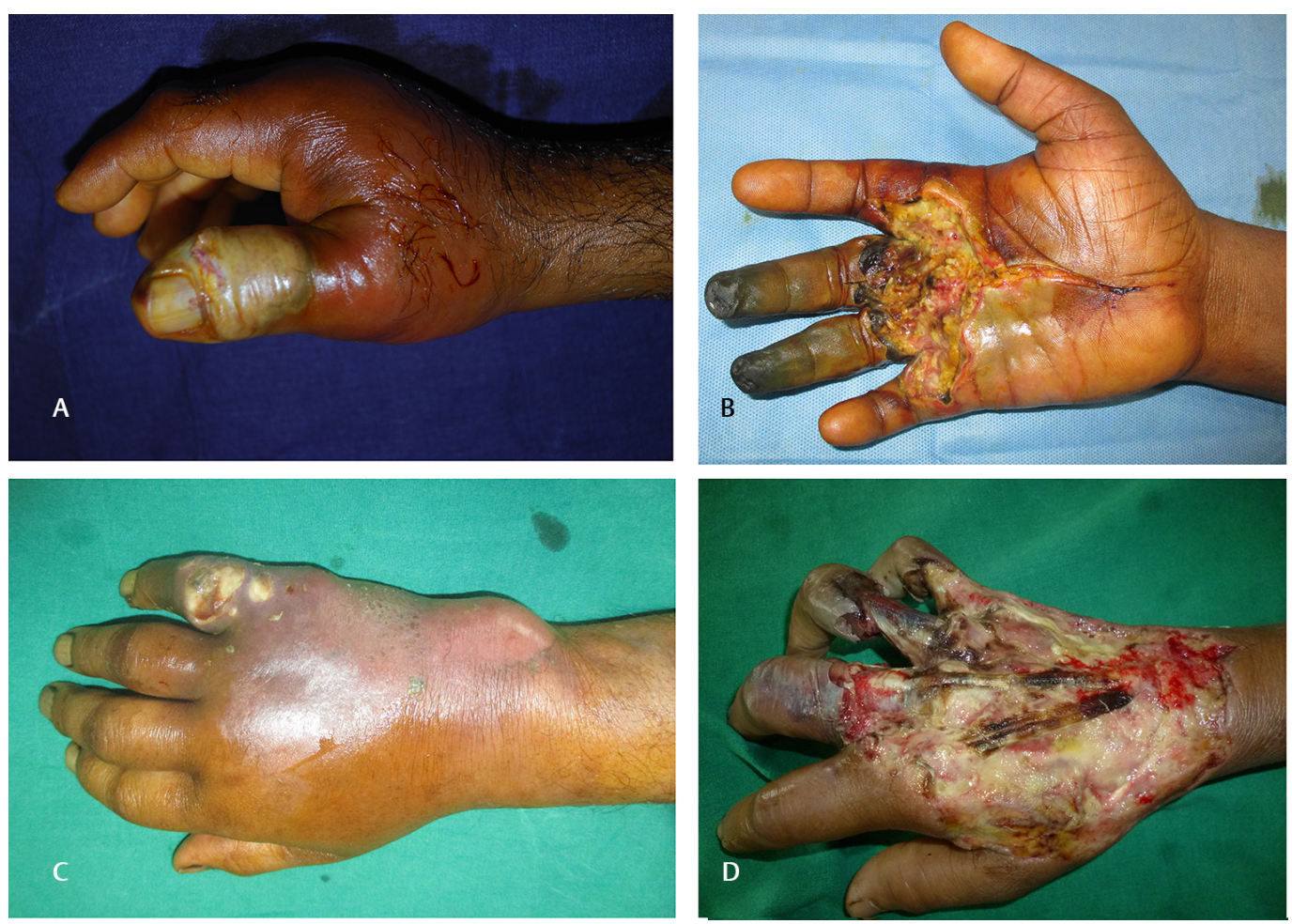

Fig. 1 (A, B, C and D) Varied presentation ranging from paronychia to necrotizing fasciitis.

underwent two or more surgeries. Flap division and surgical syndactyly separation were excluded from this count. Seven patients needed repeat debridement, and 17 patients underwent reconstructive surgery in the form of tendon repair (1), split thickness skin grafts (5), local transposition flap (1), cross finger flap (3) and groin/hypogastric flap (7) ( - Figs. 3, 4 and 5, 4 and 5). Primary flap cover was done in 3 out of the 11 patients who underwent flap cover. In the other eight patients, the mean time interval between debridement and flap cover was 15 days. The skin grafts showed 100\% take, and all the flaps survived. The mean duration of hospital stay was 6 days.

Bivariate analysis was done to assess the relation between selected independent variables (duration of diabetes, onset to presentation interval, presence of comorbidities, HbA1C, RBS, and culture characteristics) with the outcome variables (amputation and multiple procedures). ( $\mathbf{- T a b l e} \mathbf{4}$ and $\mathbf{5}$ ). Gram-negative infection was found to have a significant relationship with the risk of multiple procedures $(p=0.014)$. A significant difference was noted in the mean duration of onset of symptoms to presentation between amputation and non-amputation groups (delay of 2.9 days, $p=0.04$ ) as well as between multiple and single procedure categories (delay of 4.4 days, $p=0.02$ ) (-Table $\mathbf{6}$ ). Long duration of diabetes, presence of comorbidities, and HbA1c and RBS levels at admission did not show any significant relation to both the outcomes studied.

\section{Diabetic Hand Sepsis and Mortality}

Of the 51 patients in the study, three patients expired. Two of them died due to severity of sepsis, and one expired 3 years later due to causes unrelated to hand infection. One of the expired patients was a 70-year-old man who presented to us with necrotizing fasciitis of the forearm and hand, following a thorn prick in the hand, and presented to us 60 days later. He had a random blood glucose level of $171 \mathrm{mg} / \mathrm{dL}$ and an HbA1c of $11 \%$. Debridement was done twice; he had acute kidney injury, hypotension and diabetic ketoacidosis, and he expired on the 10th postoperative day. The second patient had an infected wound with cellulitis and presented to us after 10 days. He had a RBS level of $221 \mathrm{mg} / \mathrm{dL}$ and underwent debridement twice. He developed acute kidney dysfunction and acute respiratory distress syndrome. After 9 days of hospitalization and intensive care, he expired. The third patient had an uneventful postoperative period

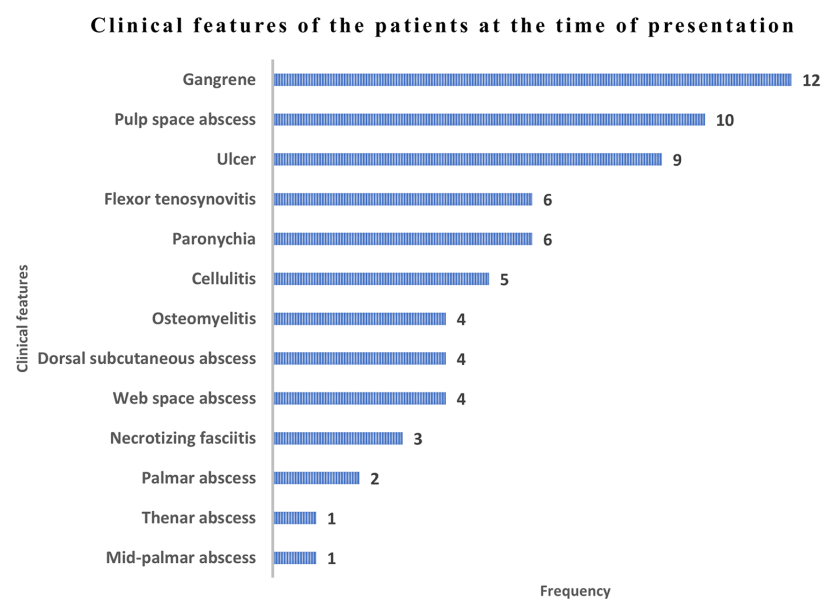

Fig. 2 Clinical features of the patients at the time of presentation and their distribution. 

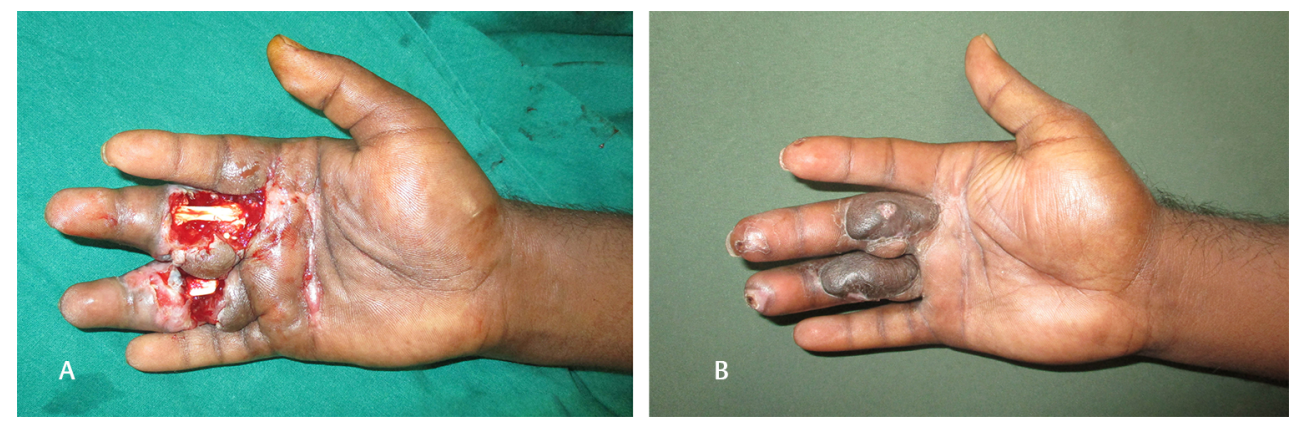

Fig. 3 A 34-year-old male with infection and soft-tissue loss over the flexor aspect of his right middle and ring fingers following a trivial injury sustained 11 days earlier. He underwent debridement of the wounds and pedicled abdominal flap cover. (A and B) 6 months follow-up pictures. Trophic changes at the tips of fingers and at the apex of the flap in the middle finger due to lack of sensation.
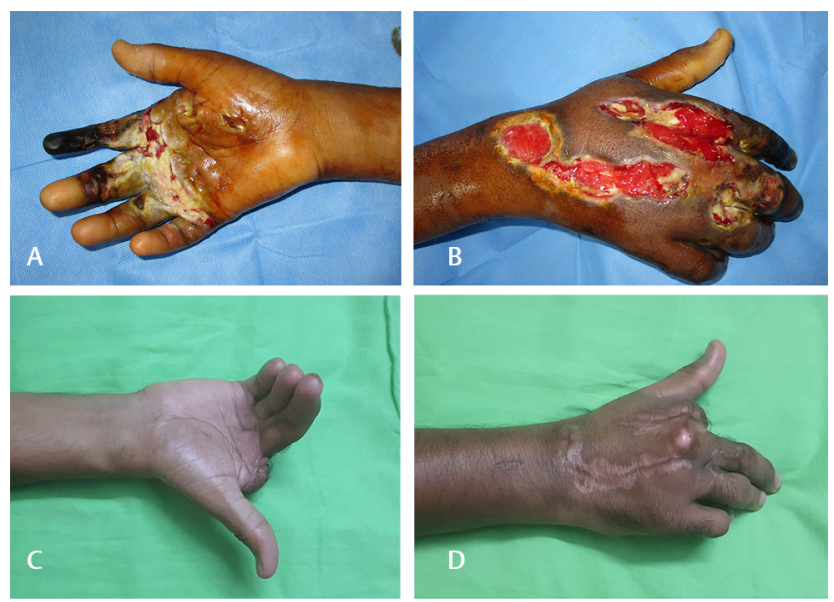

Fig. 4 (A and B) A 36-year-old male with spontaneous onset of gangrene of his right index finger presented to us 17 days later with dry gangrene of the whole index finger, slough in the distal palm, and raw areas on the dorsum of the hand. Debridement, amputation of index finger with split-thickness skin graft (SSG) cover for the dorsum done. (C and D) 10 months follow-up pictures.

for the hand infection. Three years after the hand infection episode, he underwent left below knee amputation elsewhere for diabetic foot ulcer and expired 3 weeks post amputation.

\section{Discussion}

Diabetes has a negative impact on the outcome of hand infections. Prompt diagnosis and early treatment are the keys to successful outcome in diabetic hand infections. The various factors which are likely to have an impact on the outcome were studied. We found that a delay in presentation and the type of organism causing the infection to have a significant relationship with the outcome of these infections.

\section{Age and Gender}

The mean age of presentation in our study was 56 years. Most of the studies on the topic showed a mean age between 50 and 60 years at presentation. Literature review shows that the gender affection varies with population. Our study
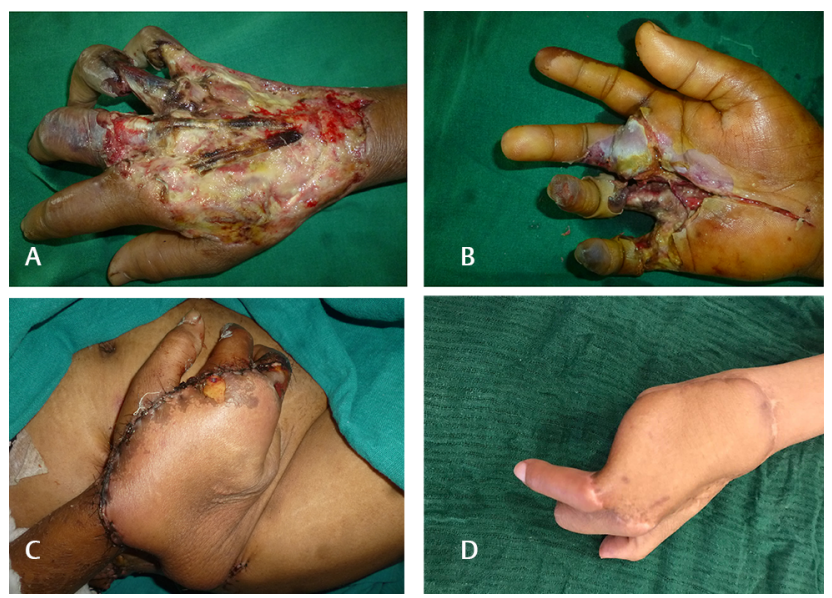

Fig. 5 (A and B) A 56-year-old lady presented to us with gangrene of the medial three fingers of her right hand following a thorn prick injury sustained 15 days earlier. (C) Debridement, amputation of the ring and little fingers with a pedicled abdominal flap cover were done. (D) 7 years follow-up picture.

showed a male preponderance $(34 / 51)$. The articles on tropical diabetic hand syndrome (TDHS) from Africa and sub-Saharan regions ${ }^{8,9,12}$ show a higher incidence in females, while those from the rest of the world show a male preponderance. ${ }^{13,14}$ This is because females are the main labour force of the family in the African homes, and due to their cultural practices, they do not frequent hospitals; hence, the delay in presentation of a post traumatic infected hand ulcer. ${ }^{9}$

\section{Duration of Diabetes}

In the present study, 27.5\% ( $n=14)$ of patients were diagnosed to have diabetes only on admission for the hand infection. This is higher than those found in studies elsewhere- $9 \%$ in the study by Gonzales et a ${ }^{11}$ and $15 \%$ in the study by Benotmane et al. ${ }^{2}$ This probably indicates poor and infrequent preventive health care check-ups done in Indian population. The ulcer in the hand led to the diagnosis of diabetes in these patients. So, for around one-third of the study population, a diagnosis of diabetes remained undetected. We could not find a significant relationship between long duration of diabetes and the outcome variables, and the above observation could have influenced it. The average duration of 
Table 4 Comparison of the selected factors with the occurrence of amputation

\begin{tabular}{|c|c|c|c|c|c|c|}
\hline \multirow[t]{2}{*}{ Variables } & \multirow[t]{2}{*}{ Categories } & \multicolumn{2}{|c|}{ Amputation } & \multirow[t]{2}{*}{ Total } & \multirow[t]{2}{*}{$p$-Value ${ }^{a}$} & \multirow[t]{2}{*}{ OR $(95 \% \mathrm{CI})$} \\
\hline & & $n$ & $\%$ & & & \\
\hline \multirow[t]{2}{*}{ Duration of DM $(n=51)$} & 5 years and above & 9 & 31.03 & 29 & \multirow[t]{2}{*}{0.95} & \multirow[t]{2}{*}{$0.96(0.29-3.18)$} \\
\hline & Less than 5 years & 7 & 31.82 & 22 & & \\
\hline \multirow{2}{*}{$\begin{array}{l}\text { Duration from onset to pres- } \\
\text { entation }(n=49)\end{array}$} & 10 days and above & 11 & 40.74 & 27 & \multirow[t]{2}{*}{0.09} & \multirow[t]{2}{*}{$3.09(0.82-11.67)$} \\
\hline & Less than 10 days & 4 & 18.18 & 22 & & \\
\hline \multirow{2}{*}{$\begin{array}{l}\text { Comorbidities other than DM } \\
(n=51)\end{array}$} & Present & 7 & 35.00 & 20 & \multirow[t]{2}{*}{0.65} & \multirow[t]{2}{*}{$1.32(0.39-4.38)$} \\
\hline & Absent & 9 & 29.03 & 31 & & \\
\hline \multirow[t]{2}{*}{$\mathrm{HbA} 1 \mathrm{C}(9 \%)(n=45)$} & $7 \%$ and above & 13 & 34.21 & 38 & \multirow[t]{2}{*}{$0.29^{b}$} & \multirow[t]{2}{*}{$3.12(0.34-28.74)$} \\
\hline & Less than $7 \%$ & 1 & 14.29 & 7 & & \\
\hline \multirow[t]{2}{*}{ RBS $(\mathrm{mg} / \mathrm{dL})(n=42)$} & 200 and above & 7 & 25.00 & 28 & \multirow[t]{2}{*}{$0.80^{b}$} & \multirow[t]{2}{*}{$0.83(0.19-3.52)$} \\
\hline & Less than 200 & 4 & 28.57 & 14 & & \\
\hline \multirow{2}{*}{$\begin{array}{l}\text { Culture characteristics } \\
(n=23)\end{array}$} & Gram-negative & 1 & 16.67 & 6 & \multirow[t]{2}{*}{$0.95^{b}$} & \multirow[t]{2}{*}{$0.93(0.08-11.17)$} \\
\hline & $\begin{array}{l}\text { Gram-positive and } \\
\text { others }\end{array}$ & 3 & 17.65 & 17 & & \\
\hline
\end{tabular}

Abbreviations: DM, diabetes mellitus; RBS, random blood sugar.

${ }^{a}$ Chi-square test.

${ }^{b}$ Fisher`s exact test.

Table 5 Comparison of the selected factors with the multiple procedure categories

\begin{tabular}{|c|c|c|c|c|c|c|}
\hline \multirow[t]{2}{*}{ Variables } & \multirow[t]{2}{*}{ Categories } & \multicolumn{2}{|c|}{$\begin{array}{l}\text { Multiple } \\
\text { procedures }\end{array}$} & \multirow[t]{2}{*}{ Total } & \multirow[t]{2}{*}{$p$-Value ${ }^{a}$} & \multirow[t]{2}{*}{ OR $(95 \% \mathrm{Cl})$} \\
\hline & & $n$ & $\%$ & & & \\
\hline \multirow[t]{2}{*}{ Duration of DM $(n=49)$} & 5 years and above & 7 & 25.93 & 27 & \multirow[t]{2}{*}{0.08} & \multirow[t]{2}{*}{$0.35(0.11-1.16)$} \\
\hline & Less than 5 years & 11 & 50.00 & 22 & & \\
\hline \multirow{2}{*}{$\begin{array}{l}\text { Duration from onset to } \\
\text { presentation }(n=47)\end{array}$} & 10 days and above & 12 & 48.00 & 25 & \multirow[t]{2}{*}{0.07} & \multirow[t]{2}{*}{$3.14(0.88-11.16)$} \\
\hline & Less than 10 days & 5 & 22.73 & 22 & & \\
\hline \multirow{2}{*}{$\begin{array}{l}\text { Comorbidities other than DM } \\
(n=49)\end{array}$} & Present & 8 & 44.44 & 18 & \multirow[t]{2}{*}{0.39} & \multirow[t]{2}{*}{$1.68(0.51-5.56)$} \\
\hline & Absent & 10 & 32.26 & 31 & & \\
\hline \multirow[t]{2}{*}{ HbA1C level $(n=44)$} & $7 \%$ and above & 14 & 37.84 & 37 & \multirow[t]{2}{*}{1.00} & \multirow[t]{2}{*}{$0.81(0.16-4.18)$} \\
\hline & Less than $7 \%$ & 3 & 42.86 & 7 & & \\
\hline \multirow[t]{2}{*}{ RBS level $(n=40)$} & 200 and above & 11 & 40.74 & 27 & \multirow[t]{2}{*}{0.89} & \multirow[t]{2}{*}{$1.10(0.28-4.26)$} \\
\hline & Less than 200 & 5 & 38.46 & 13 & & \\
\hline \multirow[t]{2}{*}{ Culture characteristics $(n=23)$} & Gram-negative & 6 & 100.00 & 6 & \multirow[t]{2}{*}{$0.014^{b}$} & \multirow[t]{2}{*}{-} \\
\hline & $\begin{array}{l}\text { Gram-positive and } \\
\text { others }\end{array}$ & 6 & 35.29 & 17 & & \\
\hline
\end{tabular}

Abbreviations: DM, diabetes mellitus; RBS, random blood sugar.

a Chi-square test.

${ }^{b}$ Fisher`s exact test.

diabetes was $6.6 \pm 7.1$ years. Wang et $\mathrm{al}^{13}$ from China in their study on hand infections in patients admitted with diabetic foot ulcer found a significant correlation between prognosis of the hand infection and longer duration ( $>3$ years) of diabetes.

\section{Onset of the Hand Infection}

Majority of patients, $58.8 \%(n=30)$ in this study could not recollect a precipitating event that led to hand infection. Probably, the trauma to their hands with reduced sensation goes unnoticed and grabs attention only when the wound gets infected. ${ }^{9}$ Gonzales et al. ${ }^{11}$ documented that 15 out of
45 patients had an unknown or spontaneous onset history, while others had crush or laceration injuries.

\section{“Onset of Symptoms to Presentation” Interval}

The mean "onset of symptoms to presentation interval" was 11.4 days (SD = 9.9 years). Mann and Peacock in their 1977 publication said that there was a lapse of 10 days before they sought medical help. ${ }^{1}$ The scene has not changed much. When it comes to tropical diabetic hand syndrome (TDHS), Abbas et $\mathrm{al}^{9}$ and Nthumba et $\mathrm{al}^{8}$ found a delay of 14 days and 23 days, respectively. On comparison, there was a statistically significant difference in 
Table 6 Comparison of the mean of the selected factors between different groups

\begin{tabular}{|c|c|c|c|c|c|c|}
\hline \multirow[t]{2}{*}{ Variables } & \multicolumn{3}{|c|}{ Amputation } & \multicolumn{3}{|c|}{ Multiple procedure } \\
\hline & $\begin{array}{l}\text { Amputation } \\
\text { status (n) }\end{array}$ & Mean (SD) & $p$-Value ${ }^{*}$ & $\begin{array}{l}\text { Multiple } \\
\text { procedure } \\
\text { status }(n)\end{array}$ & Mean & $p$-Value ${ }^{a}$ \\
\hline \multirow[t]{2}{*}{ Duration of DM (years) } & Yes (16) & $6.76(8.33)$ & \multirow[t]{2}{*}{$0.70^{\mathrm{b}}$} & Yes (18) & $3.80(5.18)$ & \multirow[t]{2}{*}{$0.02^{\#}$} \\
\hline & No (35) & $6.54(6.55)$ & & No (31) & $8.31(7.76)$ & \\
\hline \multirow[t]{2}{*}{$\begin{array}{l}\text { Onset to presentation } \\
\text { (days) }\end{array}$} & Yes (15) & $13.40(7.30)$ & \multirow[t]{2}{*}{$0.04^{b}$} & Yes (17) & $\begin{array}{l}13.18 \\
(7.28)\end{array}$ & \multirow[t]{2}{*}{$0.02^{\#}$} \\
\hline & No (34) & $10.50(10.84)$ & & No (30) & $8.80(6.55)$ & \\
\hline \multirow[t]{2}{*}{ HbA1C (\%) } & Yes (14) & $9.44(2.38)$ & \multirow[t]{2}{*}{0.23} & Yes (17) & $\begin{array}{l}10.56 \\
(2.92)\end{array}$ & \multirow[t]{2}{*}{0.44} \\
\hline & No (31) & $10.50(2.84)$ & & No (27) & $9.89(2.67)$ & \\
\hline \multirow[t]{2}{*}{ RBS (mg/dl) } & Yes (12) & $277.15(125.76)$ & \multirow[t]{2}{*}{$0.98^{\#}$} & Yes (16) & $\begin{array}{l}276.88 \\
(125.9)\end{array}$ & \multirow[t]{2}{*}{$0.91^{\#}$} \\
\hline & No (30) & $274.01(134.36)$ & & No (24) & $\begin{array}{l}280.01 \\
(139.23)\end{array}$ & \\
\hline \multirow[t]{2}{*}{ WBC count $(n)$} & Yes (6) & $8700.00(2651.04)$ & \multirow[t]{2}{*}{0.76} & Yes (8) & $\begin{array}{l}10062.50 \\
(3841.11)\end{array}$ & \multirow[t]{2}{*}{0.46} \\
\hline & No (19) & $9110.53(3094.06)$ & & No (16) & $\begin{array}{l}8956.25 \\
(1625.62)\end{array}$ & \\
\hline
\end{tabular}

Abbreviations: DM, diabetes mellitus; RBS, random blood sugar; SD, standard deviation; WBC, white blood cell.

a Independent $t$-test.

${ }^{\mathrm{b}}$ Mann-Whitney $\mathrm{U}$ test.

the mean of "onset of symptoms to presentation" interval between amputation and non-amputation groups ( $p=0.04$ ) and multiple and single procedure groups $(p=0.02)$. Early presentation to hospital is critical to the outcome. The common factors which led to delayed presentation in all the studies are ignorance of the patient or the health care provider and resorting to traditional healing methods.

\section{Presence of Comorbidities}

We did not find a relationship between the presence of comorbidities and the outcome variables. But we observed that two of our patients, who were renal transplant recipients, underwent digital amputation. This has been previously reported by Francel et al. ${ }^{15}$ where he states a $100 \%$ amputation rate in diabetic patients who had renal transplantation. Gonzales et al. ${ }^{11}$ found that the need for amputation had a correlation with renal failure, polymicrobial, anaerobic or Gram-negative infection, and deep infection.

\section{Laboratory Results}

Among the laboratory values, HbA1C and RBS at admission were analyzed and were not found to have a significant relationship with the outcomes. Gurbuz and Ekinci ${ }^{16}$ have reported that although HbA1c is a good biomarker for glucose level monitoring, it cannot predict the severity of the diabetic hand infection, and our study has also found the same. Although hyperglycemia is associated with suppression of immunity and in turn the occurrence of soft-tissue infections, we did not find a significant association between HbA1C or RBS and the outcome variables, risk of amputation and multiple procedures.

\section{Culture Characteristics}

In our study, there was equal distribution of Gram-positive and negative cultures. The patients with infections with Gram-negative cultures needed more procedures, which was statistically significant $(p=0.014)$. Significant variability has been noted among studies regarding the culture characteristics of the microorganism involved in diabetic hand infections. ${ }^{1,211,13-15,17}$ In a study on the microbiology of diabetic foot ulcers, the isolation rate of Staphylococcus species was 18.5\%, of which $80 \%$ were Staphylococcus aureus and 20\% were CoNS. ${ }^{18}$ However, in our study on diabetic hand infections, $67 \%$ of the Staphylococci were CoNS.

\section{Surgical Procedures}

We performed a total of 101 procedures in 51 patients, an average of two surgeries per patient, with eight being the maximum number of procedures done in a patient. Gonzales ${ }^{11}$ in their study on 46 patients mentioned that $50 \%$ of the patients underwent two or more procedures. Four needed either skin graft or groin flap. Mokifoya et al. ${ }^{19}$ in their study on 21 patients reported that two of their patients needed skin graft and two needed flap cover. They did a radial forearm artery flap, and both the cases suffered a partial loss. In our study, we found that seven patients required a second debridement due to fulminant infection and extension of the abscess. Skin/soft-tissue cover was needed in 17 of our patients.

We looked up the Indian studies on diabetic hand infections and found that in the study by Raveendran et al. ${ }^{5}$ the study population consisted of 39 cases admitted in their center over 6 years. The profile showed a male preponderance: $24 / 39$ patients (61.5\%). Bacteriological culture revealed 
a polymicrobial picture in $13 / 25$ (52\%) culture-positive patients. Seven patients (17.94\%) required amputation and 15 patients (38\%) required skin and soft-tissue cover; 12 needed split thickness skin grafting and three needed flap cover (two cross-finger flaps and one posterior interosseous flap). They found an association between severe necrotizing infections and the parameters: poor glycemic control, polymicrobial infection, and delay in presentation. The duration of hospitalization and amputation rates was greater in these patients. The study on the cutaneous manifestations of diabetes showed that $41 \%$ of the skin lesions were related to infections. ${ }^{6}$ Another study was a case report of two cases with TDHS, which were aggressively managed and went on to give good outcome. ${ }^{7}$

\section{Limitations}

The follow-up and long-term outcome of the patients who had undergone surgical procedures were not studied. The status of peripheral neuropathy and peripheral vascular disease was not addressed in this study. Although all the diabetic hand infection patients over a period of 4 years were included in the study, the sample size was small enough to find out any significant association between the independent and outcome variables.

\section{Conclusion}

The "onset of symptoms to presentation" interval was found to be an important variable in the prognosis of diabetic patients with hand infections. There was a difference in delay of 2.9 days and 4.4 days between the amputation/nonamputation groups and multiple/nonmultiple procedure groups, respectively, and the difference was found significant $(p=0.04, p=0.02)$. Awareness is needed to refer diabetic patients with symptoms of hand infection early enough in the disease course to avoid any delay in seeking appropriate treatment, since it can lead to loss of the limb or multiple surgeries like serial debridement and soft-tissue cover, as evidenced by our study. Hand infection with Gram-negative organisms need prompt and aggressive management to avoid serial surgeries $(p=0.014)$. In the present study, long duration of diabetes or blood glucose levels or white cell counts or presence of comorbidities were not found to be significant factors influencing the risk of multiple procedures or amputation.

\section{Funding}

The authors have no sources of financial or material funding to disclosure. No portion of this work has been previously presented or published. All authors were involved in the clinical care of the patients, design and conception of this paper, and the writing and revising process. Our study was performed in accordance with and conforming to the Declaration of Helsinki.

\section{Conflict of Interest}

None declared.

\section{Acknowledgments}

We would like to thank Dr. Sreelal T P, DM Wayanad Institute of Medical Sciences (DM WIMS), Kerala, for helping us with the statistical analysis.

\section{References}

1 Mann RJ, Peacock JM. Hand infections in patients with diabetes mellitus. J Trauma 1977;17(5):376-380

2 Benotmane A, Faraoun K, Mohammedi F, Benkhelifa T, Amani ME. Infections of the upper extremity in hospitalized diabetic patients: a prospective study. Diabetes Metab 2004;30(1):91-97

3 Stern PJ, Staneck JL, McDonough JJ, Neale HW, Tyler G. Established hand infections: a controlled, prospective study. J Hand Surg Am 1983;8(5 Pt 1):553-559

4 Maloon S, de Beer JV, Opitz M. Acute flexor tendon sheath infections. J Hand Surg Am 1990;15:474-477

5 Raveendran S, Naik D, Raj Pallapati SC, Prakash JJ, Thomas BP, Thomas N. The clinical and microbiological profile of the diabetic hand: a retrospective study from South India. Indian J Endocrinol Metab 2016;20(5):619-624

6 Chatterjee N, Chattopadhyay C, Sengupta N, Das C, Sarma N, Pal SK. An observational study of cutaneous manifestations in diabetes mellitus in a tertiary care Hospital of Eastern India. Indian J Endocrinol Metab 2014;18(2):217-220

7 Tiwari S, Chauhan A, Sethi NT. Tropical diabetic hand syndrome. Int J Diabetes Dev Ctries 2008;28(4):130-131

8 Nthumba P, Cavadas PC, Landin L. The tropical diabetic hand syndrome: a surgical perspective. Ann Plast Surg 2013;70(1):42-46

9 Abbas ZG, Lutale J, Gill GV, Archibald LK. Tropical diabetic hand syndrome: risk factors in an adult diabetes population. Int J Infect Dis 2001;5(1):19-23

10 Bahar Moni AS, Hoque M, Mollah RA, Ivy RS, Mujib I. Diabetic hand infection: an emerging challenge. J Hand Surg Asian Pac Vol 2019;24(3):317-322

11 Gonzalez MH, Bochar S, Novotny J, Brown A, Weinzweig N, Prieto J. Upper extremity infections in patients with diabetes mellitus. J Hand Surg Am 1999;24(4):682-686

12 Abbas ZG, Archibald LK. Tropical diabetic hand syndrome. Epidemiology, pathogenesis, and management. Am J Clin Dermatol 2005;6(1):21-28

13 Wang C, Lv L, Wen X, et al. A clinical analysis of diabetic patients with hand ulcer in a diabetic foot centre. Diabet Med 2010;27(7):848-851

14 Gill GV, Famuyiwa OO, Rolfe M, Archibald LK. Serious hand sepsis and diabetes mellitus: specific tropical syndrome with western counterparts. Diabet Med 1998;15(10):858-862

15 Francel TJ, Marshall KA, Savage RC. Hand infections in the diabetic and the diabetic renal transplant recipient. Ann Plast Surg 1990;24(4):304-309

16 Gürbüz K, Ekinci Y. Is the preoperative glycated hemoglobin (HbA1c) level predictive of the severity of diabetic hand infection according to surgical and clinical outcomes? Exp Clin Endocrinol Diabetes 2019;(e-pub ahead of print). doi: 10.1055/a-1025-3766

17 Pinzur MS, Bednar M, Weaver F, Williams A. Hand infections in the diabetic patient. J Hand Surg [Br] 1997;22(1):133-134

18 Padmavathy K, Krishnan RS, Padma K, Sathyapriya B. Nasal colonization of methicillin resistant Staphylococcus aureus and its plausible association with infected foot ulcers in diabetic patients. Indian J Public Health Res Dev 2019;10:182-183

19 Mofikoya BO, Ajani A, Ugburo AO, Olusoga O. Surgical outcomes of diabetic hand infections in Lagos, Nigeria. Malawi Med J 2019;31(3):198-201 